\title{
The Impact Of Marketing Innovation On The Performance Of Small And Medium Enterprises In Nigeria
}

https://doi.org/10.21272/sec.5(3).98-105.2021.

Arkila Yelmi, ORCID: https://orcid.org/0000-0001-8891-0305

Department of Business Administration and Management, Faculty of Management Sciences, Adamawa State University Mubi, Nigeria

Yakubu Yahaya, ORCID: https://orcid.org/0000-0002-9268-3130

PhD, Department of Business Administration and Management, School of Management Sciences, Abubakar Tatari Ali Polytechnic Bauchi, Bauchi state, Nigeria

Abdullahi Muhammed, ORCID: https://orcid.org/0000-0001-8530-1889

Department of Business Administration and Management, School of Information and office Technology, Abubakar Tatari Ali Polytechnic Bauchi, Bauchi state, Nigeria

Lillian Garuba Oyikwu, ORCID: https://orcid.org/0000-0002-8481-4380

Department of Business Administration and Management, School of Management Sciences, Abubakar Tatari Ali Polytechnic Bauchi, Bauchi state, Nigeria

\begin{abstract}
The intensity of global market competition has created dynamic and fast-changing business environment which has affected all enterprises including small- and medium-sized enterprises (SMEs). SMEs have, therefore, realized the need to explore, exploit and deploy marketing innovation and innovative strategies in order to stay competitive in the changing business environment. In both developed and developing countries across the world, SMEs form an important fragment of the local economic system.

Therefore, the objective of this study was to assess the impact of marketing innovation on the performance of SMEs in Nigeria. The study was guided by an epistemological research philosophy adopting a positivist research paradigm. The research design was cross-sectional survey design using both quantitative and qualitative approaches. The target population for this study was 782 registered SMEs by and the sample size was 120 respondents derived using Fisher's formulae. This study used a self-administered, closed, and open-ended questionnaire to obtain quantitative data. The used descriptive statistics such as mean, standard deviation, median and proportions using the Statistical Package for Social Sciences (SPSS) version 24 and Microsoft Excel. Regression analysis and correlation analysis were used to determine the direction and strength of the relationship between the independent and the dependent variables. The study results revealed that whereas marketing innovation had a positive and significant influence on performance of SMEs in Nigeria. Study concluded that in this ever-changing technology, adoption of various innovations by SMEs is a key component of enhancing their performance. Therefore, enterprise owners need to be proactive in adopting different innovations since they all are linked positively to the performance of enterprises.
\end{abstract}

Keywords: marketing, performance, innovation, SMEs.

JEL Classification: M13, M19.

Cite as: Yelmi, A., Yahaya, Ya, Muhammed, A. (2021). The Impact Of Marketing Innovation On The Performance Of Small And Medium Enterprises In Nigeria. SocioEconomic Challenges, 5(3), 98-105. https://doi.org/10.21272/sec.5(3).98-105.2021.

Received: 30.06 .2021

Accepted: 29.08 .2021

Published: 13.09 .2021 
SocioEconomic Challenges, Volume 5, Issue 3, 2021

ISSN (print) - 2520-6621, ISSN (online) - 2520-6214

Copyright: (C) 2021 by the authors. Licensee Sumy State University, Ukraine. This article is an open access article distributed under the terms and conditions of the Creative Commons Attribution (CC BY) license (https://creativecommons.org/licenses/by/4.0/).

\subsection{Introduction}

The intensity of global market competition has created dynamic and fast-changing business environment which has affected all enterprises including small- and medium-sized enterprises (SMEs). SMEs have, therefore, realized the need to explore, exploit and deploy management decision. Marketing innovation is a fundamental factor that increases company's profitability. In order to measure innovation, a business has to break down its marketing function into constituent parts, along with a mechanism through which to analyze the interaction between those parts. By doing this, decision-makers will finally be in a position to relate marketing expenses to shareholder value and to understand how to tie marketing initiatives back into the value created for the company. Marketing innovation is defined as implementing new marketing method that involve significant changes in the packaging, design, placement and product promotion and pricing strategy. Masood, Sadia, Multan, Saqib and Saman, (2013) opine that marketing innovation is the implementation of a new marketing methods involving significant changes in product design or packaging, product placement, product promotion or pricing. The objective of marketing innovation is to increase the sales and market share and opening new markets. The distinctive feature for the marketing innovation from the other types of innovation is the implementation of new marketing method that the firm has never been implemented before.

(Nail\&whitler 2018) posits that marketing strategy is necessary in any business organization and for it to compete in a global market it must ensure that resources are available and well utilized. The main goals of marketing innovation for business are to fill market needs, grow market share, and increase shareholder value (sperando, 2017 Iravo, Ongori and Deonir(2017) observed that one of the important questions in business has been why some organizations succeed and strategic management because a lot of strategic thinking is geared towards defining and measuring performance why others fail and this has influenced a study on strategic marketing innovation.

It is argued that for an organization to be successful it has to record high returns and identify profitability from the top to the bottom of the organization. Performance management and improvement is at the heart of (Victor $\&$ adoukonou, 2018). Identifying consumer insights and trends through marketing assists with the evaluation of cost savings and other ongoing initiatives, and may contribute to organizational growth. Marketing innovation is a method by which a firm attempts to reach its target markets. Marketing innovation starts with market research, in which needs and attitudes and competitors' products are assessed and continues through into advertising, promotion, distribution and where applicable, customer servicing, packaging, sales and distribution. Marketing innovation usually focus on delivering greater value to customers and the firm at a lower cost. However, quantifying the return on investment from marketing expenditure on activities such as advertising, promotion and distribution is one of the most complex issues facing decision makers. Marketing innovation has traditionally been viewed and treated more as an operational rather than strategic function in companies. It has focused on decisions related to analyzing and selecting target markets, product and brand development, promotion, and channels of distribution (Jean \& harelimana, 2017. This perhaps somewhat biased standpoint presents marketing as a task of creating, promoting and delivering goods and services to consumers and businesses (suidan,2018). It is generally accepted that acquiring a new customer may turn out to be considerably more expensive than building customer loyalty among firm's current customers (suidan, 2018). This strongly speaks for the need for higher levels of customer orientation among companies. Similarly to reward systems that base on short-term performance, short-term marketing focus may start working against longer-term market orientation, business performance and strategic intentions of a company.

Sanjeepan, (2017) investigate the impact of Marketing innovation on Business Performance in Small and Medium Enterprises (SMEs) in Oluyole Local Government, Ibadan, Nigeria. The study mainly focuses on the independent variables (Product, Promotion, Place, Price packaging, design, placement product promotion and pricing strategy) and dependent variables of business performance in term of profitability, market share, return on investment, and 
expansion. The researcher found out that marketing strategies (product, place, price, packaging, and after sales service) were significantly independent and joint predictors of business performance. The study however, discovered that marketing innovation has no positive significant effect on business performance. It is nevertheless crucial to acknowledge the factors mainly affecting on goodness or badness of performance. If the company is doing poorly, it has to unravel the reasons for the current situation so that it can form a plan for a brighter future. On the other hand, a firm doing well must know what the most influential factors behind its success are because only accordingly it can sustain its competitive position also in the future. To emphasize the importance of understanding long-term value of company resources,

\subsection{Statement of the problem}

The current problem facing SMEs in Nigeria today is how to overcome low sales which have greatly affected their profitability due to inefficient and effective strategic marketing innovation. Every company which intends to improve on its marketing has to create good strategic marketing innovation for its efficient and effective operations. Marketing innovation have contributed immensely towards the achievement of post purchase satisfaction, on the side of customers who -make use, of a given product in the market. Well established and implemented strategic marketing innovation have played greater roles in the success of business in Nigeria. These strategic marketing innovation if effectively used should increase the sales and profitability of such company and will also enable the company to achieve its stated goals/objectives, Nwaizugbo (2018)

Nigeria is also faced with some problems while implementing the marketing innovation with respect to SMEs profitability. The major problems that are currently face by the SMEs in Nigeria today is there is low level innovation these has led to poor performance of Small and medium scale enterprises in Nigeria. However, Nigerian manufacturing industries have been experiencing setbacks after the collapse of manufacturing companies between 2015-2017 whereby 820 companies shut down or suspended production due to economic recession (Ayodeji, 2017). This is compounded by the consequent increase in competition from imports, which has resulted in downsizing or outright closure of many manufacturing industries. Therefore, there is a great need for the Federal Government of Nigeria to foster development of SMEs among the indigenous population in order to restructure the private sector in manufacturing industries which is a powerful economic engine for growth(Ayodeji, 2017). While previous studies have made efforts to interrogate how innovations affect performance of SMEs, this study adopted a narrow context by focusing on the SMEs given their high failure rate as demonstrated above. In addition, generalizability and transferability of previous findings from such studies across boundaries need further investigation. Therefore, this study sought to determine the effect of marketing innovation on the performance of small and medium in Nigeria.

\subsection{Research Objective}

1. To examine the impact of marketing innovation on the performance of small and medium enterprises in Nigeria.

\subsection{Research Hypothesis}

The following hypotheses was tested and formulated in a null form.

$\mathbf{H}_{\mathbf{0 1}}$ Marketing innovation has no significant impact on the performance of small and medium enterprises in Nigeria.

\subsection{Justification of the study}

The uniqueness and contribution of this study is twofold: First, unlike previous studies which focus on small and medium enterprises in Nigeria, this study decomposes and studies the impact of marketing innovation. It is worth noting, understanding the unique factors that influence marketing innovation is vital for sustainable growth of small and medium enterprises and the economy at large. Second, the study adopts both analytic and descriptive methodology in an attempt to conduct an in depth investigation on causal relationship between marketing innovation and the performance of small and medium enterprises in Nigeria. The study would also contribute to the existing literature in the field of management. 


\section{Literature review}

\section{Concept of marketing innovation}

Marketing innovation is a vital prerequisite of Industry's ability to strengthen its market share and minimize the impact of the competition. Tuan, Nhan, Giang and Ngoc (2016) in their study of 'The Effects of Innovation on Firm Performance of Supporting Industries in Hanoi-Vietnam' concludes that innovative activities have a positive influence on performance of SMEs. However, the study further indicates that in support industry focus should be more on process, marketing, and organizational innovation. The study further indicates that process and organization innovation is more important than product and market organization. The study used a questionnaire that included general information, innovation activities; innovative performance and firm performance in measuring indicators on 5 point a likert scale. Another study on the effects of strategic innovation on the performance of SMEs in Nairobi county by Osuga and Namanda (2016) concludes that innovations in marketing have a strong positive association with the performance of the SMEs. This is due to the fact that customer needs and preferences keep on changing in order to adapt to the new style.

Walobwa, Ngugi and Chepkulei (2013) studied on the effect of the type of innovation on the growth of small and medium enterprises in Kenya: a case of garment enterprises in Kericho, Nairobi. This study sought to investigate, and document different types of innovations adopted by garment SMEs in Nairobi. The study evaluated whether there is any effect between the innovations adopted and growth of the enterprise. Descriptive design was used to study the research objectives. Census was conducted on the population. Questionnaires were administered to thirty-one entrepreneurs/managers of garment businesses in the study area. The study by Waloba, Ngigi and Chepkulei (2013) found out that among the types of innovation analyzed, marketing innovation contributed most to the growth of garment SMEs in Jericho market, Nairobi. However, it was also established that all types of innovation were being practiced in the sector and that innovation is very critical for SMEs to become and remain competitive in the global market. The study presented a contextual research gap since it focused on Kericho while this study focused on Nairobi. The differences in urban and rural setting can bring out differences in the challenges SMEs face in the two contexts. The findings of the study can thus not be generalized to an urban setting.

Nyachwaya (2017) studied on the influence of marketing innovation on the performance of soapstone small and medium enterprises in Kisii, County. The specific objectives of the study is to establish the contribution of marketing innovation in achieving superior performance among the SMEs and also to determine the extent to which SMEs in the sector are responsive to changes in the target market. The study adopted a cross sectional descriptive survey design whereby all the 46 registered Soapstone SMEs in Kisii County were targeted. Data was collected through the use of a semi-structured questionnaire and the data collected was analyzed using descriptive measures. The findings of the study are that the marketing innovation principles took the form of collaboration with firms in their distribution line and among themselves, continuous ideation of new ideas, value creation and implementation of the marketing ideas. The influence of marketing innovation on the SMEs performance was manifested in terms of increase development of products that are perceived by customers as more reliable than competitors' products, increased product range and revenue generated.

From the regression equation, the coefficient of independent variables is positive, and this implies that the adoption of marketing innovations by the soapstone SMEs has positively affected their performance. In line with the findings of the study, the researcher concluded that for effective implementation of marketing innovation principles, there is need for the SMEs to appreciate and incorporate these principles, set aside requisite resources to support policy and related strategies. There is need to incorporate both the County and National Governments for policy formulation targeting the SMEs as well as for support in infrastructural development and coordination through established agencies with requisite skills capable of supporting them in capacity building, protection of patents and intellectual property, marketing, gathering information on market trends and policy formulation.

Kimani (2016) study examined market orientation in Micro and Small Enterprises in Kenya in relation to their performance. Micro and Small Enterprises are faced with many problems that include stiff competition by multinationals and government owned organizations and this has implication on their performance. With their large resource base and support from their parent organizations and the government, subsidiaries of multinationals 
and government organizations are a force to reckon with in the marketplace. Market Orientation is a strategy that firms can use to gain competitive advantage and enhance their performance. Dimensions of market orientation include innovativeness, competitive aggressiveness, pro-activeness and information sharing.

\section{Theoretical framework}

The theoretical foundation of this study is based on the influential theory of resource-based theory (RBT) and its extended DCT. The RBT and DCT have being predominantly used to deepen the understanding regarding how resources are identified, selected, deployed and coordinated to develop innovative marketing methods. Firms' resources may also include all assets, organizational processes, attributes, information and the knowledge to conceive and implement strategies to develop, manufacture and deliver products to customers (Barney, 1991). In order to create a market advantage, resources must be valuable (exploit opportunities and/or neutralize threats in a firm's environment), rare among a firm's current and potential competitors, inimitable and non-substitutable "VRIN" (Barney, 1991). Apart from the RBT which focusses on both internal tangible and intangible assets (Barney, 1991), this study also adopts the DCT which focuses on the processes used in exploiting firms' resources (Vassolo and Anand, 2008). These processes represent the capabilities that managers possess to integrate, develop and reconfigure their competences to match and address rapidly changing environments (Genç et al., 2013; Jiao et al., 2010; Teece et al., 1997). In view of this, the integration of resources and capabilities creates competences relevant to sustaining firms' market advantage (Genç et al., 2013). The relevance of RBT and DCT to this study is that SMEs possess unique marketing resources and capabilities such as knowledge (quality information and activities), expertise, appropriate technology and adequate finances relevant to anticipating and responding to changing customer needs with innovative marketing tools.

\section{Empirical review}

Baldaachino (2009) studied entrepreneurial creativity and innovation in Malta. The objective of the study was to explore ways in which start-up entrepreneurs are creative and innovative and how that has led to their survival in the business they are engaged in. Data was collected by means of combination of in-depth interviews and telephone questionnaires with entrepreneurs who started up an enterprise in Malta between January 2002 and June 2007. Data collection and analysis took place in two phases: Phase One utilized a qualitative method of data collection while Phase Two made use of the quantitative method to substantiate the findings of the first phase of research. The data collected in Phase One was fully analyzed before Phase Two was conducted, as the preliminary findings from the qualitative research were fed into the quantitative part of the study for further investigation. The results indicated that creativity and innovation were deemed important for initial survival and for continued growth and success, with frequent references to initial innovative business ideas, a subsequent flow of new ideas for products or services, creative solutions to problems and innovative business processes.

Walobwa, Ngugi and Chepkulei (2013) studied on the effect of the type of innovation on the growth of small and medium enterprises in Kenya: a case of garment enterprises in Kericho, Nairobi. This study sought to investigate, and document different types of innovations adopted by garment SMEs in Nairobi. The study evaluated whether there is any effect between the innovations adopted and growth of the enterprise. Descriptive design was used to study the research objectives. Census was conducted on the population. Questionnaires were administered to thirty-one entrepreneurs/managers of garment businesses in the study area. The study by Waloba, Ngigi and Chepkulei (2013) found out that among the types of innovation analyzed, marketing innovation contributed most to the growth of garment SMEs in Jericho market, Nairobi. However, it was also established that all types of innovation were being practiced in the sector and that innovation is very critical for SMEs to become and remain competitive in the global market. The study presented a contextual research gap since it focused on Kericho while this study focused on Nairobi. The differences in urban and rural setting can bring out differences in the challenges SMEs face in the two contexts. The findings of the study can thus not be generalized to an urban setting.

Nyachwaya (2017) studied on the influence of marketing innovation on the performance of soapstone small and medium enterprises in Kisii, County. The specific objectives of the study is to establish the contribution of marketing innovation in achieving superior performance among the SMEs and also to determine the extent to which SMEs in the sector are responsive to changes in the target market. The study adopted a cross sectional 
descriptive survey design whereby all the 46 registered Soapstone SMEs in Kisii County were targeted. Data was collected through the use of a semi-structured questionnaire and the data collected was analyzed using descriptive measures. The findings of the study are that the marketing innovation principles took the form of collaboration with firms in their distribution line and among themselves, continuous ideation of new ideas, value creation and implementation of the marketing ideas. The influence of marketing innovation on the SMEs performance was manifested in terms of increase development of products that are perceived by customers as more reliable than competitors' products, increased product range and revenue generated.

From the regression equation, the coefficient of independent variables is positive, and this implies that the adoption of marketing innovations by the soapstone SMEs has positively affected their performance. In line with the findings of the study, the researcher concluded that for effective implementation of marketing innovation principles, there is need for the SMEs to appreciate and incorporate these principles, set aside requisite resources to support policy and related strategies. There is need to incorporate both the County and National Governments for policy formulation targeting the SMEs as well as for support in infrastructural development and coordination through established agencies with requisite skills capable of supporting them in capacity building, protection of patents and intellectual property, marketing, gathering information on market trends and policy formulation.

Validity and Reliability of Research Instruments: The instruments used in this study were submitted to a panel of experts for validation. The panel carried out a content analysis of each of the questionnaires and eliminated items found to be irrelevant to the research problem. After necessary modifications, the panel of experts recommended the use of the instruments for the study. The scales were subjected to further item analysis as to determine their psychometric soundness as indicated in Table1 below:

Table 1. Summary of Results of the Measurement Instruments Validation

\begin{tabular}{|c|c|c|c|c|c|c|}
\hline Scale & No of Items & Meaning Bartlett & KMO & $\begin{array}{c}\text { Eigenvalue of the } \\
\text { principal } \\
\text { Component }\end{array}$ & $\begin{array}{c}\% \text { of the } \\
\text { variance }\end{array}$ & $\alpha$ of Cronbach \\
\hline $\begin{array}{c}\text { Marketing } \\
\text { innovation } \\
\text { Questionnaire }\end{array}$ & 7 & $\begin{array}{c}\mathrm{p}=.000 \\
\text { (significant) }\end{array}$ & 0.854 & 277 & $81.05 \%$ & 0.94 \\
\hline
\end{tabular}

Source: Field Report, 2021.

Table 2. Distribution of respondents by impact of marketing innovation on the organizational performance

\begin{tabular}{|l|l|l|}
\hline \multicolumn{1}{|c|}{ Statement } & \multicolumn{1}{|c|}{ Mean } & Rank \\
\hline The company is keen on new product development & 4.01 & Accepted \\
\hline Sometimes Innovation can be difficult due to lack of funds or in-house capacity & 3.98 & Accepted \\
\hline We need to deliver newer products and services to maintain our competitiveness & 3.76 & Accepted \\
\hline We outsource some innovation to other companies that can do it better and faster & 3.65 & Accepted \\
\hline Innovation has helped us to create and deliver value faster than our competitors & 4.12 & Accepted \\
\hline Marketing innovation is one way the company has innovated and remained competitive & 4.15 & Accepted \\
\hline Innovativeness is a major contributor to improved performance & 4.09 & Accepted \\
\hline Grand mean & 3.96 &
\end{tabular}

Source: Survey field 2021.

In Table 2, the grand mean of 3.96 which is above the criterion mean of 3 shows that respondents agreed that marketing innovation has significant effect on organizational performance. Results also indicate that on average; the respondents agreed that marketing innovation is one way the company has innovated and remained competitive, outsourcing had enabled the organization to develop new products quickly enough for the market. Innovativeness is a major contributor to improved performance, the company is keen on new product development and Sometimes Innovation can be difficult due to lack of funds or in-house capacity with mean values of 4.15, $4.12,4.09,4.01$ and 3.98 respectively. This implies that marketing innovation is an alternative paradigm to an organizational performance in a global competitive environment. 


\section{Methodology}

Research Design: The study adopted a descriptive research design. Descriptive research design was employed because is an efficient way of gathering data to help address a research questions and one can collect unbiased data and develop sensible decision based on analyzed results (Van de van, 2007).

Sampling Method and Sample Size: Purposive random sampling technique was used to select two management staff each from the sixty (60) selected manufacturing companies in Nigeria State totaling one hundred and twenty (120) respondents as a sample size for the study.

Data Collection Instruments: A structured questionnaire was used to collect relevant information from the study's participants.

\section{Conclusion}

This study sought to answer the question of what shaped SMEs in a developing country context. This research also sought to answer the question of how marketing innovation contributed to SMEs performance. The study provided evidence that certain learning related factors did potentially contribute to shaping entrepreneurial orientation and contribute to increased earnings.

The findings shows that focus marketing innovation have a significant impact on the performance of SMEs in Nigeria. Subsequently, the study concludes that management of SMEs companies should adopt marketing innovation strategy in other to gain competitive advanta.

\section{Recommendations}

In recognition of Bwisa and Gacuhi (1997) who concluded that together the combination of management and technology provide an ideal underpinning for technology innovation and SMEs, it is recommended that schools incorporate entrepreneurial modules within the core curriculum. This supports Drucker (1985) cited in McCormick and Maalu (2011) who stated that systematic innovation is an entrepreneurs' tool and the innovation process should be taught and learnt in a pedagogic and didactic way.

The government agencies and financial institutions are to review the effectiveness of their schemes for motivating SMEs as the results indicate that these two stakeholders are perceived not to be contributing to an environment that is 133 conducive for entrepreneurship. Financial assistance remains the greatest need. It is recommended that SMEs owners should consider other ways of raising seed capital for their new entrepreneurial ventures as the results indicated that financial institutions may not provide the necessary finance.

Funding: self-funded.

Author contribution: conceptualization, Arkila Yelmi, Yakubu Yahaya, Abdullahi Muhammed, Lillian Garuba Oyikwu; data curation, Arkila Yelmi, Yakubu Yahaya, Abdullahi Muhammed, Lillian Garuba Oyikwu; formal analysis, Arkila Yelmi, Yakubu Yahaya, Abdullahi Muhammed, Lillian Garuba Oyikwu; funding acquisition, Arkila Yelmi, Yakubu Yahaya, Abdullahi Muhammed, Lillian Garuba Oyikwu; investigation, Arkila Yelmi, Yakubu Yahaya, Abdullahi Muhammed, Lillian Garuba Oyikwu; methodology, Arkila Yelmi, Yakubu Yahaya, Abdullahi Muhammed, Lillian Garuba Oyikwu; project administration, Arkila Yelmi, Yakubu Yahaya, Abdullahi Muhammed, Lillian Garuba Oyikwu; resources, Arkila Yelmi, Yakubu Yahaya, Abdullahi Muhammed, Lillian Garuba Oyikwu; software, Arkila Yelmi, Yakubu Yahaya, Abdullahi Muhammed, Lillian Garuba Oyikwu; supervision, Arkila Yelmi, Yakubu Yahaya, Abdullahi Muhammed, Lillian Garuba Oyikwu; validation, Arkila Yelmi, Yakubu Yahaya, Abdullahi Muhammed, Lillian Garuba Oyikwu; visualization, Arkila Yelmi, Yakubu Yahaya, Abdullahi Muhammed, Lillian Garuba Oyikwu; writing - original draft, Arkila Yelmi, Yakubu Yahaya, Abdullahi Muhammed, Lillian Garuba Oyikwu; writing - review \& editing, Arkila Yelmi, Yakubu Yahaya, Abdullahi Muhammed, Lillian Garuba Oyikwu. 


\section{References}

1. Ayodeji, O. B. (2017). Economic Characteristics And Financial Performance Of Selected Manufacturing Companies In Nigeria. Nigeria: Babcock University. Available at: [Link].

2. Kimani, W. (2016). Market Orientation and Business Performance in Kenyan SME's Unpublished PhD dissertation, Nairobi: United States International University-Africa. Available at: [Link].

3. Masood, M., Sadia, S., Multan, P., Saqib N., \& Saman, N. (2013). Effects of Innovation Types on Firm Performance: an Empirical Study on Pakistan's Manufacturing Sector. Pakistan Journal of Commerce and Social Sciences, 7(2), 243-262. Available at: [Link].

4. Minniti, M., \& Naudé, W.A. (2010). What Do We Know about the Patterns and Determinant of Female Entrepreneurship across Countries? European Journal of Development Research, 1(2), 1-17. [CrossRef].

5. Nakora, J.O., Tarus, B.K., Belgut, K., \& Kipchirchil, K.E. (2015). Effect of Strategic Orientation on Performance of Small and Medium Enterprises: Evidence from Kenya. International Journal of Economics, Commerce and Management, 3(11), 336-348. [CrossRef].

6. Nurulhasanah, Zulnaidi., Y., \& Rafisah., M., R. (2016). The Challenges among Malaysian SME: A Theoretical Perspective. World Journal of Sciences, 6(2), 124-132. Available at: [Link].

7. Nwaizugbo, I.C., \& Anukam, A.I (2008). Assessment of entrepreneurial marketing practices among small and medium scale enterprise in Imo State Nigeria: Prospects and challenges. Review of Contemporary Business Research, 3(1), 77-98. Available at: [Link].

8. Nyachwaya, P. M. (2017). Influence of marketing innovations on the performance of soapstone small and medium enterprises in Kisii County. Unpublished PhD dissertation, Nairobi: University of Nairobi. [Link].

9. Osuga, P. O. (2016). The Effects of Strategic Innovation On The Performance Of SMEs In Nairobi County. Unpublished PhD dissertation, Nairobi: United States International University, Africa. Available at: [Link].

10. Tuan, N., Nhan, N., Giang., P. \& Ngoc., N. (2016). The Effects of Innovation on Firm Performance of Supporting Industries in Hanoi-Vietnam. Journal of Industrial Management, 9(2), 413-431. [CrossRef].

11. Walobwa, N. D., Ngugi, J. K., \& Chepkulei, B. (2013). Effect of the type of innovation on the growth of small and medium enterprises in Kenya: a case of garment enterprises in Jericho, Nairobi. European Journal of Management Sciences and Economics, 1(2), 49-57. Available at: [Link]. 